\title{
Colitis Cystica Profunda
}

\section{- Report of a Surgical Case-}

\section{YASUYUKI SHINOHARA, SEISHIRO YAMASHITA, MINORU MORIMATSU. TERUYUKI NAKASHIMA AND TATESHI FUJIYOSHI*}

\author{
Department of Pathology, Kurume University School of Medicine, \\ Kurume, 830 and *Mitsui Hospital, Ohmuta, 836 Japan
}

Received for publication September 24, 1981

\begin{abstract}
Summary: A surgical case of colitis cystica profunda of localized type was described. To prevent unnecessary radical operations, importance of histological differenciation of colitis cystica profunda, especially, from well-differentiated adenocarcinoma was stressed.
\end{abstract}

Key words: colitis cystica profunda - hamartoma - well-differentiated adenocarcinoma - mucinous carcinoma - submucosal tumor

\section{Introduction}

Colitis cystica profunda is a rare, benign lesion principally involving the rectum. This condition has often been confused with a malignant lesion, because patients usually present with symptoms of rectal bleeding, muco-sanguinous stool, diarrhea, or tenesmus, in addition to a palpable rectal mass. Histologically, the lesion is also somewhat confusing: mucosal-lined cysts in the muscularis mucosa or submucosa. This lesion is gradually gaining recognition through sporadically reported cases. However, unnecessary, radical operations are still performed. We present a surgical case of localized colitis cystica profunda with pathological detail to stress the importance of this lesion in the differential diagnosis of well differentiated adenocarcinoma.

\section{Case Report}

A 49-year-old male was admitted to hospital for evaluation of rectal pain which had recently increased in intensity. $\mathrm{He}$ noted a 20 year history of alternating frequent diarrhea and constipation, and consultation with several other local physicians. About 10 years prior to admission, his condition was diagnosed as "irritable colon". He also experienced occasional anal bleeding. He had no history of dysentery. On admission his general condition was good, and his chest and abdomen were normal. On rectal examination a soft mass was palpable in the posterio-lateral wall at $6 \mathrm{~cm}$ from the anus. Barium enema examination revealed a large sessile polypoid tumor and a closely proximal ulcer (Fig. 1). Proctosigmoidoscopy showed a raised, erythematous area and an ulcer covered with sloughed tissue (Fig. 2). Laboratory data were unremarkable. The lesion was considered clinically malignant and perineal rectal resection was performed by means of "pull-through" method.

Macroscopically, the resected specimen shows an elevated, soft submucosal tumor with two ulcers at its edge (Fig. 3). Cyst formation with gelatinous content is seen in the submucosa. Microscopically, low 

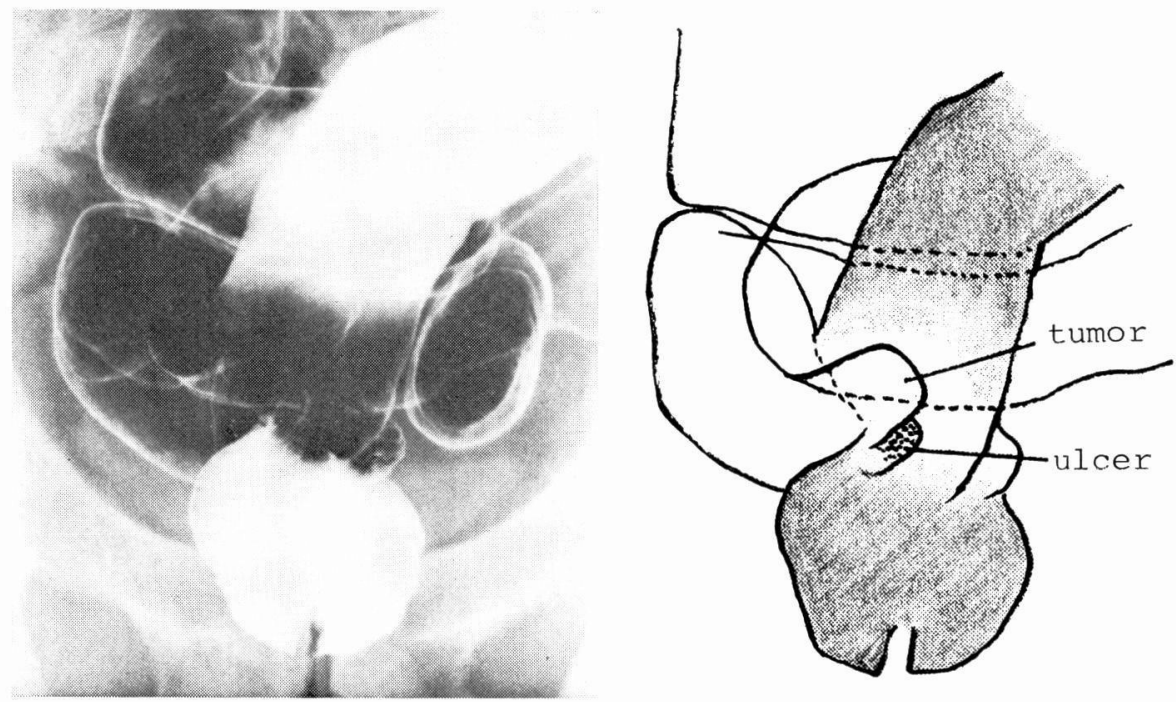

Fig. 1. Barium enema. Frontal view showing a sessile tumor and an ulcer.

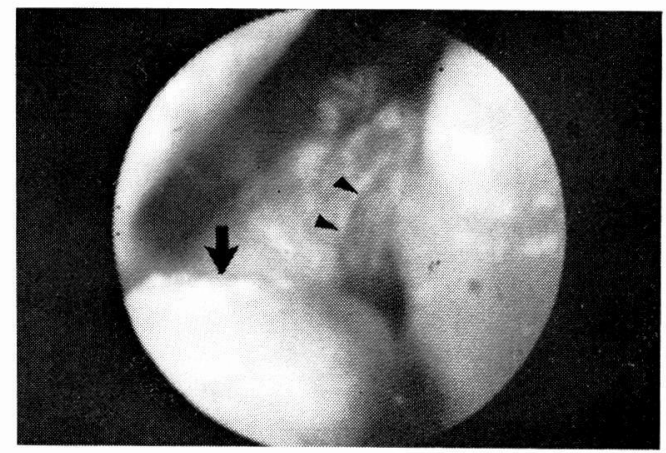

Fig. 2. Endoscopic view showing a raised, nodular mass (arrow) with an ulcer (arrow head).

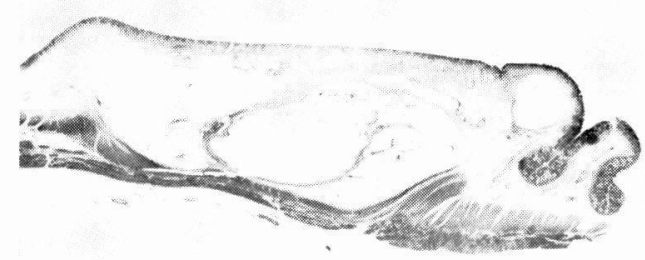

Fig. 4. Low-power photomicrograph of a rectal section. Note the many cystic spaces in the submucosa, in part, compressing the circular muscle layer. The overlying mucosa is atrophic. $\times 5, \mathrm{H}$ and $\mathrm{E}$ )

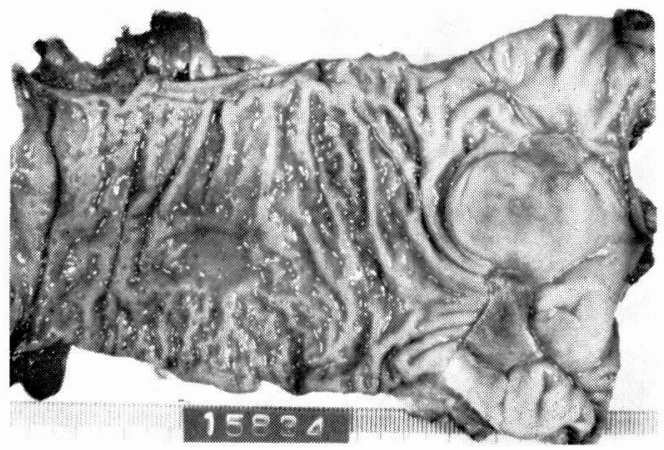

Fig. 3. Resected rectum fixed in formalin, showing an elevated, round lesion with two ulcers at its edge.

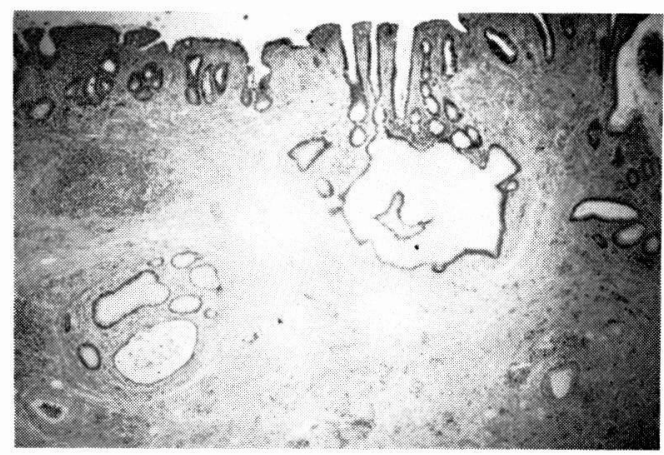

Fig. 5. High-power view of another section, showing cystic dilatation of glands passing through the muscularis mucosa and mild chronic inflammation around the cysts. $(\times 100, \mathrm{H}$ and $\mathrm{E})$ 
power reveals large, cystic spaces in the submucosa, filled with mucin and lined in part with flattened epithelial cells (Fig. 4). The overlying mucosa is atrophic and accompanied by a chronic inflammatory process. A higher power view shows cyst formation without atypism which penetrates the muscularis mucosa into the submucosa. It also shows cysts communicating with the rectal lumen through glandular tubules (Fig. 5). Associated mild inflammation is present around the cysts.

\section{Discussion}

Colitis cystica profunda was first described over a century ago by Virchow in 1863. In 1957, Goodall and Sinclair re-introduced the term to modern literature, reporting two cases of their own and reviewing the older literature. In 1979, Barcia and Washburn reported a case and reviewed the modern medical literature, including 64 cases. In Japan, Kobayashi was the first to describe a case of colitis cystica profunda. About twenty cases have subsequently been reported in the Japanese literature (Tasaka, et al. 1976; Nagasako, et al. 1977).

The pathogenesis of this condition is still in dispute. Goodall and Sinclair believed the cysts resulted from the extention of mucosal epithelium into the submucosa under conditions, such as mucosal ulceration and destruction of the muscularis mucosa. In 1966, Epstein pointed out the congenital weakness or damage by an inflammatory disease in the muscularis mucosa and the possibilty of re-epithelization of deep undermining ulcers. In 1967, Wayte and Helwing classified colitis cystica profunda into two types, diffuse and localized, based on 24 cases from the files of Armed Forces Institute of Pathology. They reported that all cases of localized type showed histologic evidence of an associated chronic proctitis and half of them presen- ted microscopic surface ulceration. They agreed with Goodall and Sinclair that granulation tissue tracts passing through the muscularis mucosa represented the cause of implantation of mucosa into the submucosa. In another view, Allen considered hamartomatous pathogenesis because of the preponderance of this lesion in young adults; he used the term "hamartomatous inverted polyps". In our own case (localized type), ulcers were in close proximity to the tumor. Based on microscopic evidence, mucosal herniation into the submucosa is believed to result from damage to the muscularis mucosa secondary to ulceration.

In addition, an interesting lesion was incidentally found apart from the tumor. In this lesion a defect of circular muscle layer and herniation of mucosa into the submucosal space was recognized, which may be called a microscopic diverticulm. There was no further evidence to prove the relation between this incidental finding and the tumor. However, it may support consideration for congenital weakness of muscularis mucosa as a cause of colitis cytica profunda, as noted by Epstein.

Symptoms and signs of colitis cystica profunda are similar to those of colon carcinoma (Barcia and Washburn, 1979). Biopsy specimens may also present the suggestion of well-differentiated adenocarcinoma because of the presence of glandular elements penetrating the muscularis mucosa into the submucosa. The histologic key points to differentiate colitis cystica profunda from well-differentiated adenocarcinoma or mucinous carcinoma are 1) some glands may have slight atypism but no malignancy, 2) epithelia of glands are lined in mono-layer but not in multilayers, 3) in the mucous lakes, there may be some atypical cells but no signet-ring cells, and 4) glands present simple dilatation but no intraglandular papillation. Therefore, it should be emphasized that glandular formation in the submucosa 
should not be interpreted as malignancy without comfirmational cytologic evidence. Since clinical symptoms and signs of colitis cystica profunda and carcinoma may be identical, the pathologist provides the key to accurate diagnosis and preventing unnecessary radical operations.

\section{References}

Allen, M. S. (1966). Hamartomatous inverted polyps of the rectum. Cancer, 19, 257-265.

Barcia, P. J. and Washburn, M.E. (1979). Colitis cystica profunda: An unusual surgical problem. Am. Surg. 45, 61-66.

Epstein, S. E., Ascari, W. Q., Ablow, R. C., Seaman, W.B. and Lattes, R. (1966). Colitis cystica profunda. Am. J. Clin. Pathol. 45,
186-201.

Goodall, H. B. and Sinclair, I. R.S. (1957). Colitis cystica profunda. J. Pathol. Bact. 73, 33-42.

Kobayashi, S. (1973). Colitis cystica profunda. Stomach and Intestine, 8, 164. (in Japanese)

Nagasako, K.,Nakae, Y., Kitao, Y. and Aoki, G. (1977). Colitis cystica profunda: Report of a case in which differentiation from rectal cancer was difficult. Dis. Col. and Rect. 20, 618-624.

Tasaka, K., Watanabe, E., Enjoji, M. and Matsuura, R. (1976). Colitis cystica profunda. Stomach and Intestine, 11, 503-508.

VIRchow, R. (1863). Die Krakhaften Geschwulste, Berlin: A. Hirschwald. 1, 243.

Wayte, D.M. and Helwig, E. B. (1967). Colitis cystica profunda. Am. J. Clin. Pathol. 48, 159-169. 